\title{
Aberrant DNA methyltransferase expression in pancreatic ductal adenocarcinoma development and progression
}

Jun Gao ${ }^{1 \dagger}$, Lihua Wang ${ }^{1 \dagger}$, Jinkang $\mathrm{Xu}^{2 \dagger}$, Jianming Zheng ${ }^{3}$, Xiaohua Man ${ }^{1}$, Hongyu Wu${ }^{1}$, Jin Jin ${ }^{1}$, Kaixuan Wang ${ }^{1}$, Huasheng $\mathrm{XiaO}^{4}$, Shude $\mathrm{Li}^{1 *}$ and Zhaoshen $\mathrm{Li}^{1^{*}}$

\begin{abstract}
Background: Altered gene methylation, regulated by DNA methyltransferases (DNMT) 1, 3a and 3b, contributes to tumorigenesis. However, the role of DNMT in pancreatic ductal adenocarcinoma (PDAC) remains unknown.

Methods: Expression of DNMT 1, 3a and 3b was detected in 88 Pancreatic ductal adenocarcinoma (PDAC) and 10 normal tissue samples by immunohistochemistry. Changes in cell viability, cell cycle distribution, and apoptosis of PDAC cell lines (Panc-1 and SW1990) were assessed after transfection with DNMT1 and 3b siRNA. Levels of CDKN1A, $\mathrm{BCl}-2$ and Bax mRNA were assessed by qRT-PCR, and methylation of the Bax gene promoter was assayed by methylation-specific PCR (MSP).

Results: DNMT1, 3a and 3b proteins were expressed in 46.6\%, 23.9\%, and 77.3\% of PDAC tissues, respectively, but were not expressed in normal pancreatic tissues. There was a co-presence of DNMT3a and DNMT3b expression and an association of DNMT1 expression with alcohol consumption and poor overall survival. Moreover, knockdown of DNMT1 and DNMT3b expression significantly inhibited PDAC cell viability, decreased S-phase but increased G1-phase of the cell cycle, and induced apoptosis. Molecularly, expression of CDKN1A and Bax mRNA was upregulated, and the Bax gene promoter was demethylated. However, a synergistic effect of combined DNMT1 and 3b knockdown was not observed.

Conclusion: Expression of DNMT1, 3a and 3b proteins is increased in PDAC tissues, and DNMT1 expression is associated with poor prognosis of patients. Knockdown of DNMT1 and 3b expression arrests tumor cells at the G1 phase of the cell cycle and induces apoptosis. The data suggest that DNMT knockdown may be a novel treatment strategy for PDAC.
\end{abstract}

Keywords: PDAC, DNA methyltransferases (DNMTs), Immunohistochemistry, siRNA

\section{Introduction}

Pancreatic cancer is the fourth most common cause of cancer death in the world. Pancreatic ductal adenocarcinoma (PDAC) accounts for $95 \%$ of pancreatic cancer. To date, most PDAC patients are diagnosed at advanced stages and die within 6-12 months. The overall 5-year survival rate for pancreatic adenocarcinoma is approximately $6 \%[1,2]$. The risk factors for PDAC include cigarette

\footnotetext{
*Correspondence: lishude57@126.com; lizhaoshen111@gmail.com ${ }^{\dagger}$ Equal contributors

${ }^{1}$ Department of Gastroenterology, Changhai Hospital, The Second Military Medical University, Shanghai 200433, China

Full list of author information is available at the end of the article
}

smoking, heavy alcohol consumption, family history, chronic pancreatitis, and diabetes mellitus [3]. Other inconsistent risk factors include coffee, meat and fish consumption [3,4]. In addition, epidemiological evidence increasingly suggests that environmental exposures induce epigenetic modifications, altering the expression of tumor suppressor genes and oncogenes, which may be causal for pancreas tumorigenesis [5].

Altered DNA methylation, such as global hypomethylation or regional hypermethylation, is one of the most consistent epigenetic changes in human cancer. Promoter hypermethylation of tumor suppressor genes is the most common epigenetic change observed in human cancers.

\section{Ciomed Central}


To date, three DNA methyltransferases (DNMTs) that are responsible for DNA methylation have been identified in mammalian cells. DNMT1 is primarily a DNA maintenance methyltransferase, as it methylates hemimethylated DNA during DNA replication in vitro and in vivo [6]. DNMT3a and DNMT3b are de novo methyltransferases and show similar activity on unmethylated and hemimethylated DNA [7,8]. Additionally, DNMT2 contains the full set of C-terminal catalytic domain conserved motifs, but it lacks the $\mathrm{N}$-terminal regulatory domain characteristic of eukaryotic DNMT [9]. The methyltransferase activity of the recombinant DNMT2 protein is weak in vitro and in vivo [10].

Overexpression of DNMT1 3a, and 3b has been reported in a variety of cancers, such as gastric, hepatocellular, colorectal, endometrioid, prostate, breast, lung cancers, and cervical cancer [11-14]. In PDAC tissues, aberrant expression of DNMT1 and DNMT3a proteins [15-18], as well as DNMT1, 3a and 3b mRNA has been reported [19]. However, some inconsistencies were reported regarding the association with clinicopathological features and prognosis due to a small sample size. Additionally, there have been no reports regarding biological behavior alterations of PDAC cells after knockdown of DMNT expression and the underlying molecular events in vitro. Thus, in this study, we analyzed the expression of DNMT1, DNMT3a and DNMT3b proteins in PDAC tissue specimens and investigated their association with clinicopathological features and patient survival. Then, we knocked down DNMT expression using siRNAs to assess the effects on the regulation of biological behavior of PDAC cells and the underlying molecular mechanisms.

\section{Materials and methods}

\section{Patients and tissue samples}

Eighty-eight PDAC patients who had a surgically resected pancreas between January 2007 and June 2009 at the Changhai Hospital of the Second Military Medical University were recruited. None of the patients received preoperative chemotherapy or radiotherapy. Tumor and adjacent normal tissue specimens were collected in accordance with Human Subject Guidelines of the University of Washington, and this study was approved by our Institutional Review Board. The clinicopathological parameters included age, gender, smoking, alcohol consumption, serum CEA, serum CA199, location of tumor, size of tumor, nerve infiltration, metastasis of lymph nodes, tumor differentiation, and TNM staging. The post-surgery followup was conducted quarterly until January 2012. Tobacco smoking was defined as at least one cigarette per day for no less than one year. Alcohol consumption was defined as a one-time intake of at least $50 \mathrm{~g}$ of Chinese liquor, $250 \mathrm{ml}$ of wine or $500 \mathrm{ml}$ of beer at least once a week for a minimum of 1 year.

\section{Immunohistochemistry}

Serial tissue sections (4 ìm thickness) were prepared from paraffin-embedded tissue blocks. The sections were deparaffinized and rehydrated, and then endogenous peroxidase activity was blocked with $3 \%$ hydrogen peroxide solution for $5 \mathrm{~min}$ and subjected to antigen retrieval in a microwave oven at $95^{\circ} \mathrm{C}$ for $12 \mathrm{~min}$ by immersion in antigen retrieval solution $(10 \mathrm{mM}$ sodium citrate buffer, $\mathrm{pH}$ 6.0). This was followed by a blocking step with $1 \%$ fetal calf serum for $20 \mathrm{~min}$ at room temperature. After that, the sections were incubated overnight at $4^{\circ} \mathrm{C}$ with a primary antibody including a rabbit polyclonal anti-DNMT1 antibody (1:100; Abcam, \#ab19905), an anti-DNMT3a antibody (1:100; Abcam, \#ab4897), or a mouse polyclonal anti-DNMT3b antibody (1:100; IMGENEX, \#IMG-184A) followed by incubation with a secondary antibody (antimouse or anti-rabbit/ Universal Immuoperoxidase Polymer, 1:200 dilution, DAKO company, USA) at room temperature for 45 to $60 \mathrm{~min}$. DAB was used for color reaction and Mayer's hematoxylin for counterstaining. Breast and colon cancer tissue sections known for elevated DNMT1, 3a, and $3 \mathrm{~b}$ expression were used as a positive control, as recommended by the manufacturer's instruction. The specificity of DNMT1, 3a and 3b was verified by replacing the primary antibody with a normal serum.

Two pathologists (JZ and XM), blinded to the clinicopathological data of each section, reviewed and scored the stained sections. Nuclear staining was considered a positive stain for DNMT1, 3b, and 3a. The different staining density regions, including high, moderate, low and negative staining areas, were captured with a digital camera (Olympus U-TV0.5XC-3, 6B05290, Japan). Each region was counted for a mean of 1,000 tumor cells per case (range, 800 to 1500). According to previous studies, a section with $\geq 20 \%$ positively stained tumor cells was defined as positive protein expression $[17,20]$. Color intensity was not evaluated because the stains of DNMT1, $3 \mathrm{a}$, and $3 \mathrm{~b}$ in most of the samples had similar color intensity.

\section{PDAC cell line and culture}

The poorly differentiated PDAC cell line Panc- 1 and the well-differentiated cell line SW1990 were obtained from ATCC (Manassas, VA). Cells were cultured in 96-well or 6-well tissue culture plates in Dulbecco's modified Eagle's medium (DMEM, Invitrogen, Carlsbad, CA, USA) containing $10 \%$ fetal bovine serum (FBS, Invitrogen) at $37^{\circ} \mathrm{C}$ and $5 \% \mathrm{CO}_{2}$.

RNA isolation and quantitative-reverse transcription polymerase chain reaction (qRT-PCR)

Total RNA was isolated using a Trizol reagent (Invitrogen) and was then reversely transcribed into cDNA using a PrimeScript $^{\text {TM }}$ RT kit (TakaRa, Dalian, China). The 
expression of DNMT1, DNMT3b, Bax, Bcl-2, CDKN1A, and $18 \mathrm{~S}$ was detected by $\mathrm{qPCR}$ (primers are listed in Additional file 1: Table S1) in ABI7500 (Applied Biosystems, Foster City, CA, USA). The program had an initial denaturation at $95^{\circ} \mathrm{C}$ for $1 \mathrm{~min}$ followed by 40 cycles of $95^{\circ} \mathrm{C}$ for $15 \mathrm{~s}$ and $60^{\circ} \mathrm{C}$ for $15 \mathrm{~s}$. The relative quantity (RQ) was determined using the $2^{(-\ddot{A} \mathrm{~A} C t)}$ method, $18 \mathrm{~S}$ mRNA was used as reference gene, and each experiment was repeated six or eight times.

\section{Construction of DNMT siRNA vectors and gene transfection}

The DNMT1 and 3b-specific siRNA duplexes were chosen from the GenBank sequences (accession \#NM_001379.1 and \#NM_175849.1, respectively) and synthesized by Ambion Inc. (Austin, TX, USA). The DNMT1 siRNA sequences were 5'-GGAUGAGAAGAGACGUAGAtt-3' and
5'-UCUACGUCUCUUCUCAUCCtg-3', and the DNMT3B siRNA sequences were $5{ }^{\prime}$-GCUCGUCUCCUAUCGAAA Att-3' and 5'-UUUUCGAUAGGAGACGAGCtt-3'. Negative control siRNA was also purchased from Ambion Inc. (Catalog \#4390843). Final concentrations were 7 nM. The OptiMEM (Gibco BRL Inc.) and Lipofectamine 2000 Transfection Kits (Invitrogen) were used for siRNA transfections. Cells were plated at $1 \times 10^{5}$ cells per well in culture dishes for overnight growth and transfected by siRNA on the following day. Six hours after transfection, the medium was removed and replaced with DMEM, and the cells were allowed to grow for $48 \mathrm{~h}$. Then, viability, apoptosis, cell cycle and gene expression were assayed.

\section{Protein extraction and western blot}

Total cellular protein was extracted from cells using an M-PER mammalian protein extraction buffer (Pierce,

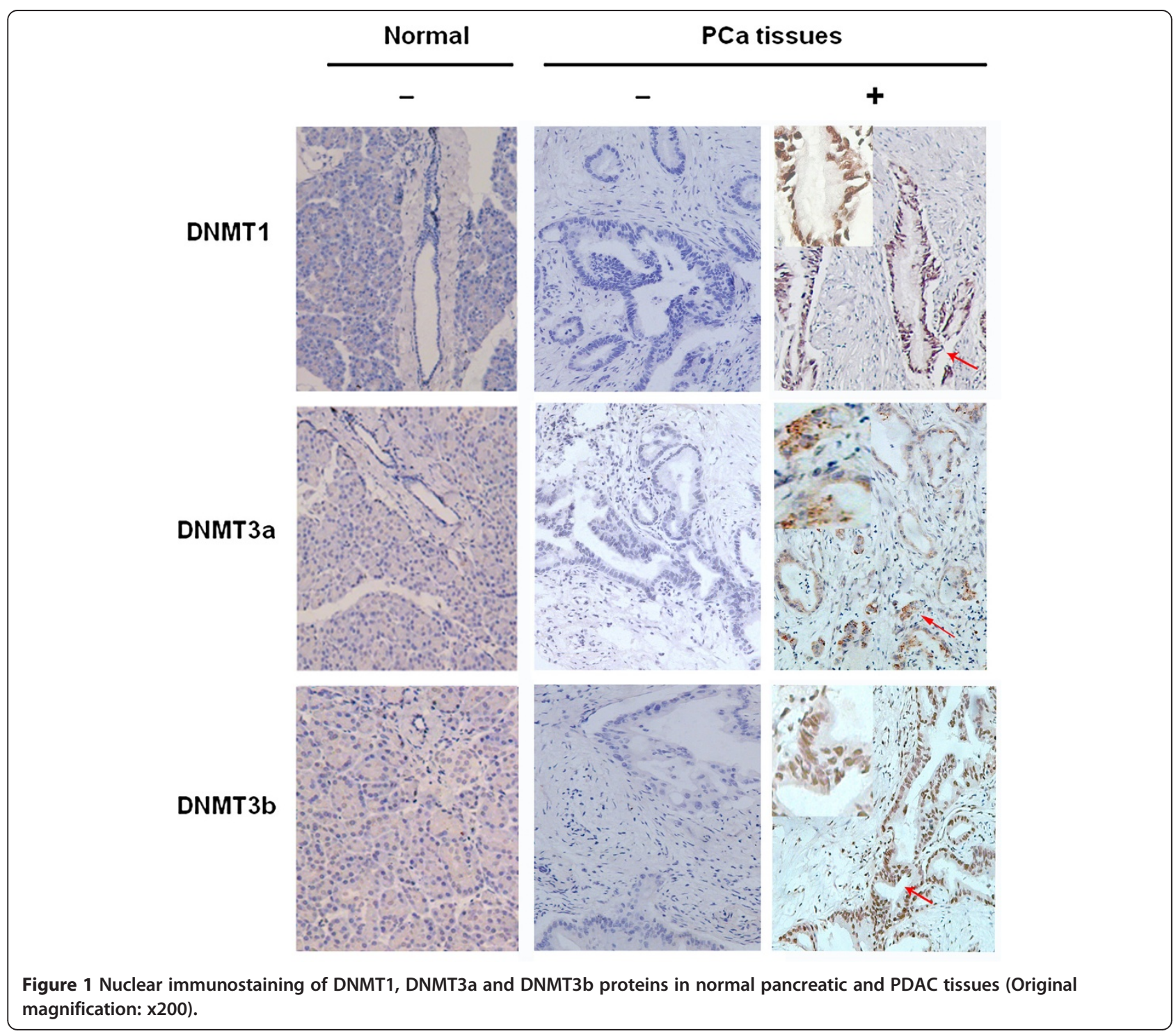


Rockford, IL) containing $0.5 \mathrm{mM}$ PMSF. The protein samples were subjected to sodium dodecyl sulfate polyacrylamide gel electrophoresis (SDS-PAGE, 12\%) and electronically transferred onto PVDF membranes (Millipore, Billerica, MA, USA). The membranes were incubated with an anti-DNMT1 antibody (1:250, Abcam, Cambridge, MA, USA), an anti-DNMT3b (1:250, Imogene, Italy) or an anti-â-actin (1:5000, Sigma, St Louis, MO, USA) antibody at $4^{\circ} \mathrm{C}$ overnight, followed by a secondary antibody for $2 \mathrm{~h}$ at room temperature. The protein bands were detected with enhanced chemiluminescence (ECL) reagent (Pierce).

\section{Cell viability Tetrazolium Salt-8 (WST-8) assay}

Briefly, cells were transfected with DNMT1, DNMT3B or negative control siRNA oligonucleotides. Seventy-two hours later, 10 il of WST-8 reagent was added to each well and incubated for an additional $4 \mathrm{~h}$. The absorbance rate was then measured at $450 \mathrm{~nm}$ with an ELISA plate reader (Thermo ELISA Reader, USA).

\section{Flow cytometry assay}

Apoptosis levels were detected using flow cytometry (Becton Dickinson) with an Annexin V-FITC Kit (Jingmei Biotech Company, Shanghai, China), while cell cycles were analyzed with propidium iodide (PI) staining.

\section{Methylation-specific PCR (MSP)}

Genomic DNA was extracted from cultured cells using a standard proteinase $\mathrm{K}$ and phenol-chloroform extraction protocol. One microgram of genomic DNA was subjected to treatment with the EZ DNA Methylation $\mathrm{Kit}^{\mathrm{m}}{ }^{\mathrm{m}}$ (Zymo Research, Orange, CA, USA) according to the manufacturer's instructions. The bisulfite modified DNA was then suspended in $20 \mathrm{il}$ of deionized water and used immediately or stored at $-80^{\circ} \mathrm{C}$ until use. Two microliters of the bisulfite modified DNA from each sample was used as templates for methylation and unmethylation reactions. The primers of methylation-specific PCR sequences of Bax gene are shown in Additional file 1: Table S2. The PCR conditions were as follows: $95 \mathrm{C}$ hot start for $5 \mathrm{~min}$, then 40 repetitive cycles of denaturation $(95 \mathrm{C}$ for $30 \mathrm{~s}$ ), annealing ( $56 \mathrm{C}$ for $30 \mathrm{~s}$ for methylation detection, $53 \mathrm{C}$ for $30 \mathrm{~s}$ for unmethylation detection), extension (72 C $30 \mathrm{~s}$ ), and a final $5 \mathrm{~min}$ extension at $72 \mathrm{C}$. PCR products (20 i $\mathrm{i}$ ) were resolved on a $2 \%$ agarose gel.

\section{Statistical analysis}

Statistical analysis was performed with SPSS version 13 (SPSS Inc., Chicago, IL). The correlation among expression of the three DNMTs was analyzed with a Kendall's tau-b test. The correlation between the positive rate of DNMT expression and the clinicopathological characteristics of PDAC patients, as well as the difference of the variables (such as expression of DNMT1 and DNMT3b
mRNA vs. tumor cell viability, apoptosis and cell cycle distribution, and expression of CDKN1A, Bcl-2, and Bax mRNA) between the differential siRNA transfected groups, were analyzed with a Mann-Whitney U test. Univariate survival analysis was performed with a Kaplan-Meier log-rank test, while multivariate survival analysis was performed with a Cox Regression test. A two-tailed $\mathrm{P}<0.05$ was considered statistically significant.

\section{Results}

\section{Aberrant expression of DNMT1, $3 a$ and $3 b$ in PDAC} tissues

Positive staining of DNMT1, 3a, and 3b protein in PDAC tissues was observed in the cell nuclei with diffuse and/or various staining patterns by immunohistochemistry, while there was no positive staining in the adjacent normal tissues (Figure 1). The expression rates of DNMT1, DNMT3a and DNMT3b proteins were $48.9 \%$ (43/88), $23.9 \%(21 / 88)$ and $77.3 \%$ (68/88), respectively, in the PDAC tissue samples. In addition, DNMT3b expression significantly co-presented with DNMT3a expression ( $\mathrm{P}=0.025$ with Kendall's tau-b test), i.e., $95.2 \%$ cases that were positive for DNMT3a were also positive for DNMT3b, but not with DNMT1 expression.

\section{Association of DNMT1, 3a or 3b expression with clinicopathological characteristics and prognosis of the patients}

The association of DNM1, 3a, and 3b expression with clinicopathological features of PDAC patients was determined. The data showed that DNMT1 expression was significantly associated with alcohol consumption, whereas the other features did not show any associations (Additional file 1: Table S3). We followed the patients for a median follow-up time of 18 months

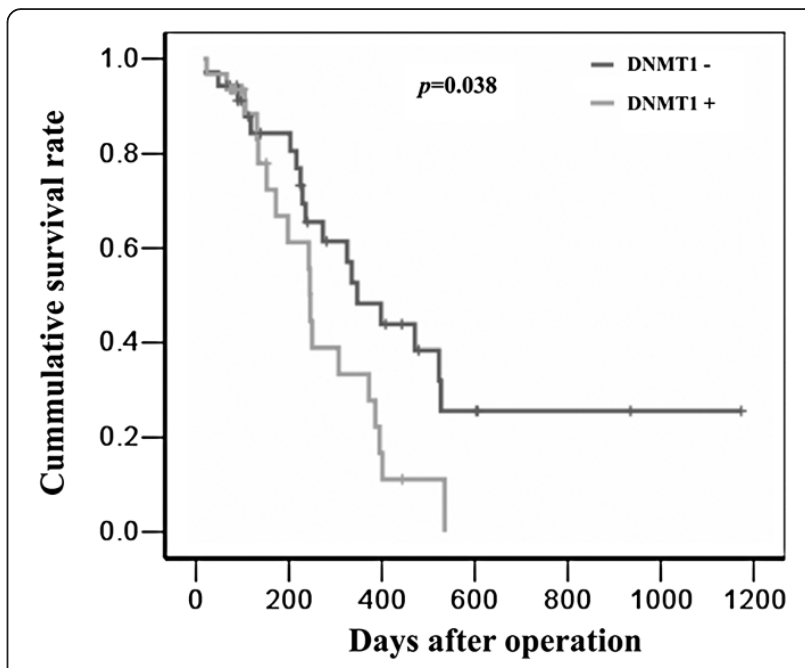

Figure 2 Kaplan-Meier survival curves of overall survival in PDAC patients $(\mathrm{N}=66)$ according to DNMT1 expression. 


\section{A}

B
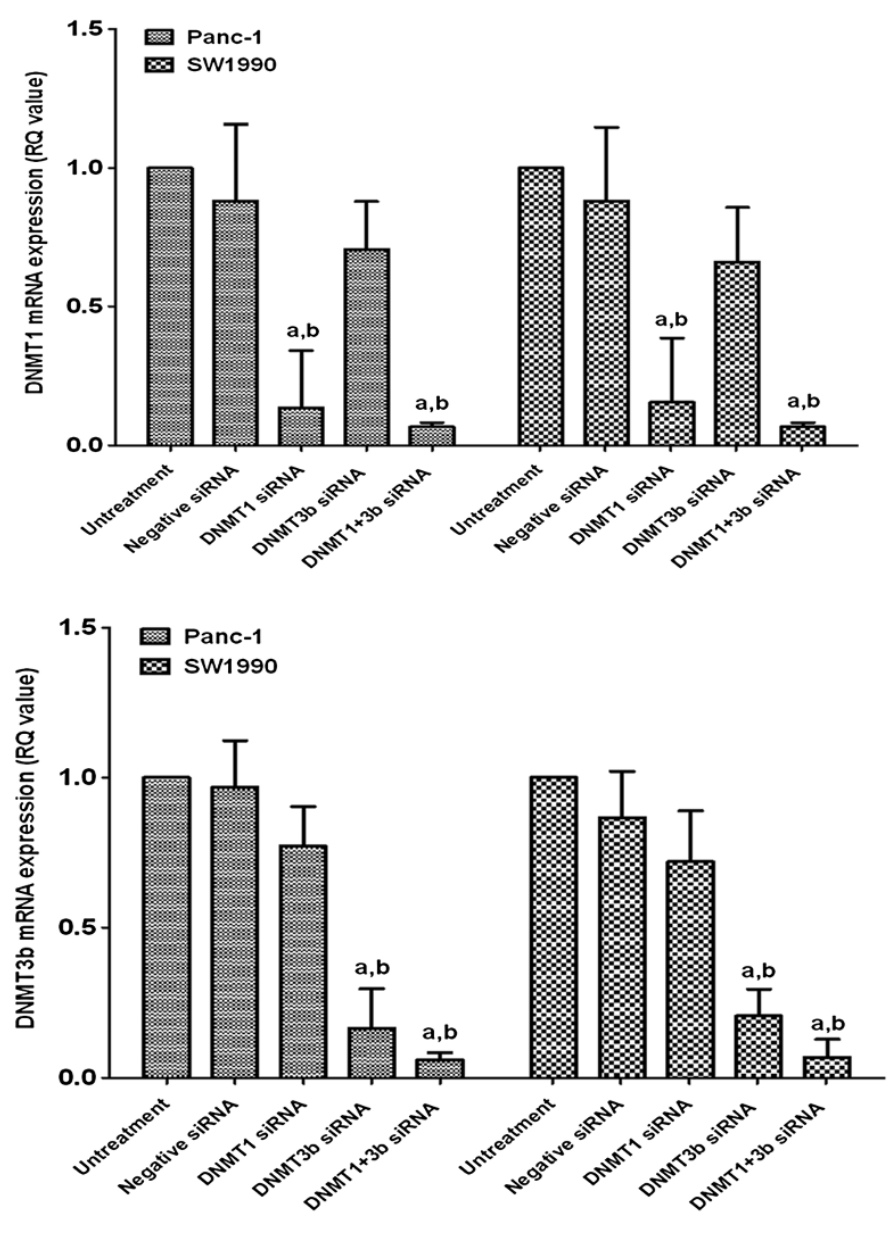

C

Panc-1

SW1990

\begin{tabular}{ccccc}
\hline \multirow{2}{*}{ Untreated } & Negative & DNMT1 & DNMT3b & DNMT1+3b \\
& siRNA & siRNA & siRNA & siRNA
\end{tabular}

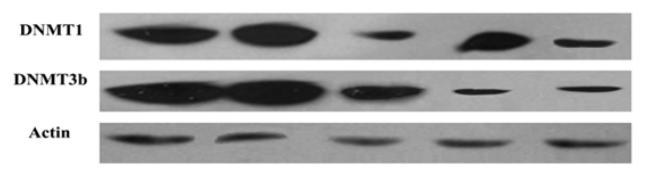

\begin{tabular}{ccccc}
\hline \multirow{2}{*}{ Untreated } & Negative & DNMT1 & DNMT3b & DNMT1+3b \\
& siRNA & siRNA & siRNA & siRNA
\end{tabular}

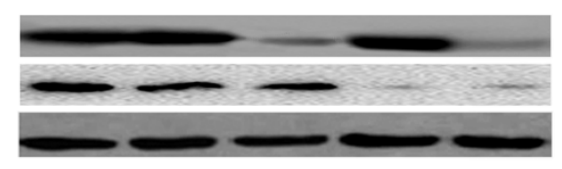

Figure 3 Knockdown of DNMT1 and DNMT3b expression in PDAC cells. DNMT1 siRNA, DNMT3b siRNA, or their combination was transiently transfected into PDAC cell lines and then subjected to qRT-PCR $\mathbf{( A , B )}$ and western blotting $\mathbf{( C )}$ analysis for DNMT1 and DNMT3b expression. $a, p<0.05$ compared with the untreated cells. $b, p<0.05$ compared with the negative siRNA cells. The data are shown as the mean \pm SD of six independent experiments.

(ranging between one and 60 months), but twentytwo patients were lost the follow-up data. A univariate survival analysis was used to assess the impact of clinicopathological characteristics and DNMT1, DNMT3a and DNMT3b expression on patient survival. As shown in Figure 2, positive DNMT1 expression was significantly associated with poor overall survival (the median overall survival time: 11.6 months for positive vs. 8.2 months for negative), a high TNM stage, poor differentiation, lymph node metastasis and serum CEA (Additional file 1: Table S4). The multivariate survival analysis, in which the significant variants from the univariate survival analysis were inputted into the Cox regression model, identified DNMT1 positive expression, poor differentiation and serum CEA as independent prognostic factors for poor overall survival (Additional file 1: Table S5).

\section{Effects of DNMT1 and DNMT3b siRNA on regulation of} PDAC cell viability, apoptosis, and cell cycle distribution The rates of aberrant DNMT1 and DNMT3b expression were much higher than that of DNMT3a in PDAC, and 

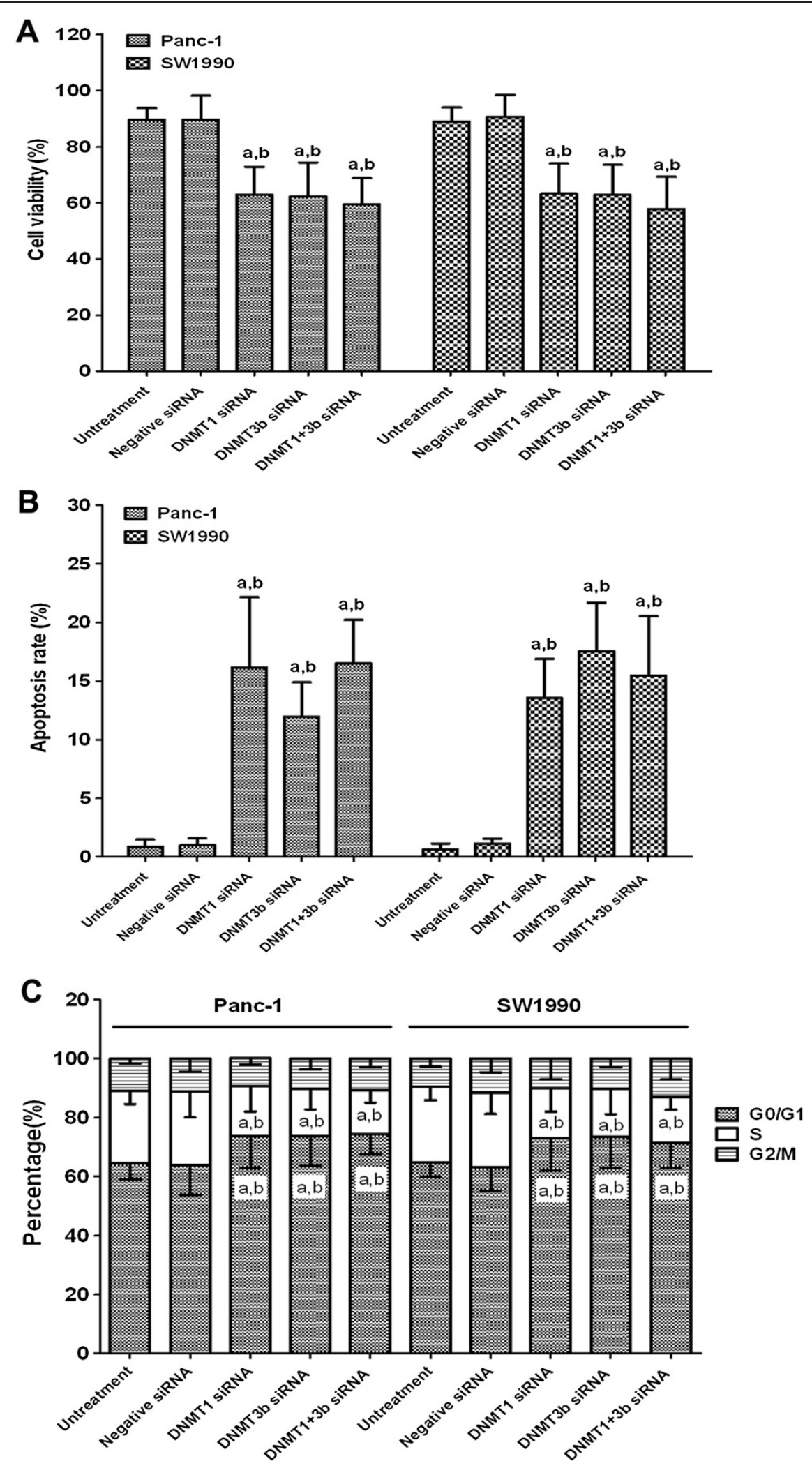

Figure 4 Effects of DNMT1 and DNMT3b siRNA on cell viability (A), apoptosis (B) and cell cycle distribution (C). a, $p<0.05$ compared with the untreated cells. $b, p<0.05$ compared with the negative siRNA-transfected cells. The data are shown as the mean \pm SD of eight independent experiments. 

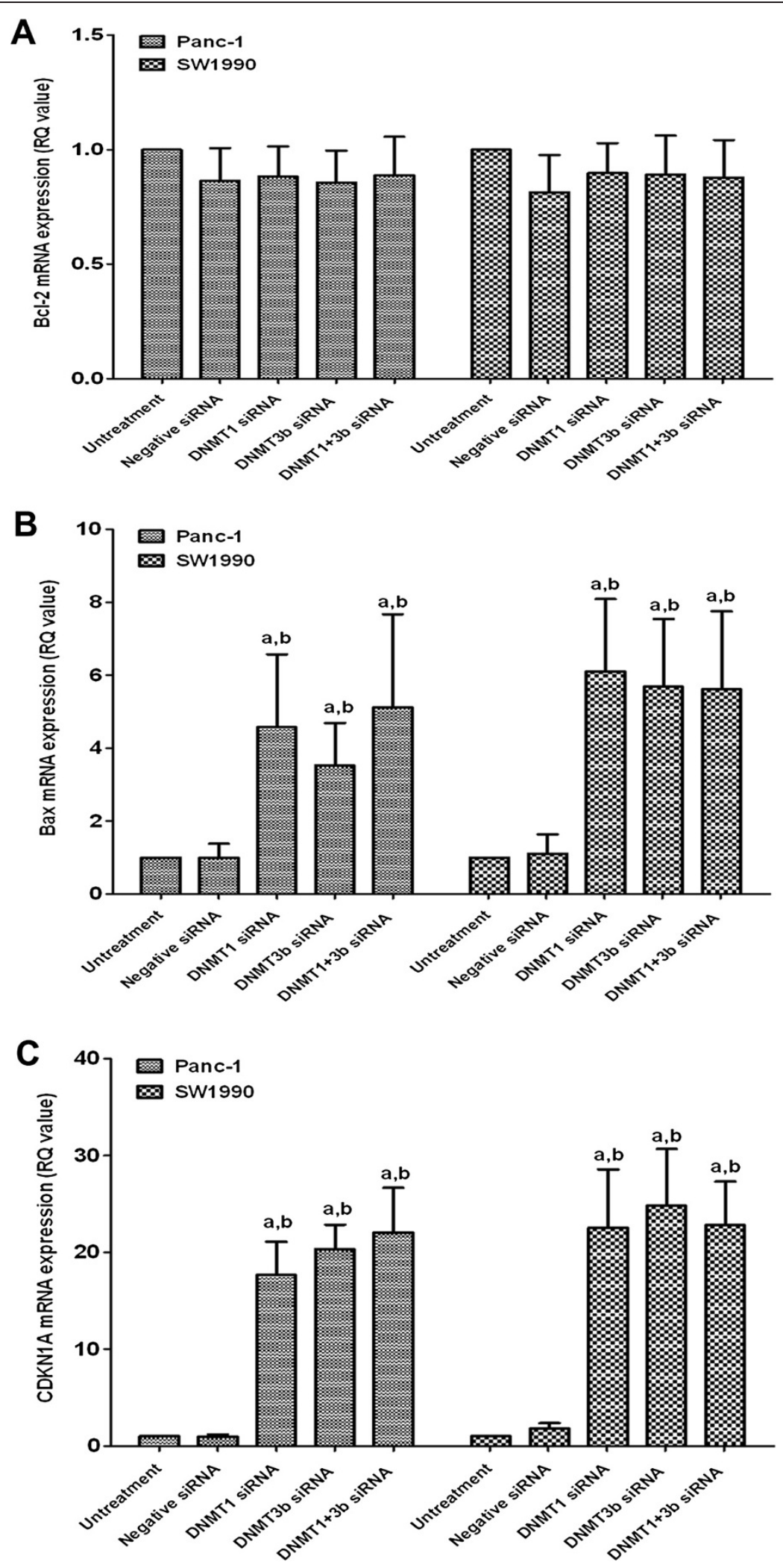

Figure 5 Effects of DNMT1 and DNMT3b siRNA on the regulation of Bcl-2 (A), Bax (B) and CDKN1A (C) expression. $a, p<0.05$ compared with the untreated cells. $b, p<0.05$ compared with the negative siRNA-transfected cells. The data are shown as the mean SD of six independent experiments. 
95.2\% of the cases positive for DNMT3a were also positive for DNMT3b. Thus, we knocked down DNMT1 and $3 \mathrm{~b}$. It is possible that DNMT3a could also play a role in PDAC progression. PDAC cell lines Panc-1 (poorly differentiated) and SW1990 (well-differentiated) were assessed. As shown in Figure 3, both qRT-PCR and Western blot data showed that transfection of DNMT1 and DNMT3b siRNA significantly reduced expression of their corresponding mRNA and protein. Transfection of either DNMT1 or DNMT3b siRNA significantly inhibited the viability of PDAC cells and decreased the number of cells in the S-phase, increased the number of cells in the G0/G1-phase, and induced apoptosis, with no significant difference between DNMT1 and DNM3b (Figure 4). Combination of DNMT1 or DNMT3b siRNA did not have any synergistic effects.

\section{Effect of DNMT1 and DNMT3b siRNA on the modulation of CDKN1A, BCl-2, and Bax expression}

The expression of the cell cycle-related molecule CDKN1A and the apoptosis-related molecule Bcl-2 and Bax was detected by qRT-PCR. As shown in Figure 5, expression of CDKN1A and Bax mRNA was significantly upregulated in the DNMT1 siRNA, DNMT3b siRNA, and DNMT1 + DNMT3b siRNA groups, whereas Bcl-2 mRNA was not significantly changed in all groups. However, the combination of DNMT1 and DNMT3b siRNA did not have a synergistic effect. Additionally, the methylation status of the Bax promoter was determined by methylation-specific PCR (MSP). The demethylation effects of either DNMT1 or DNMT3b siRNA or their combination are shown in Figure 6. These results suggest that upregulated Bax mRNA expression may be due to DNA demethylation.

\section{Discussion}

In the current study, we showed that the altered expression of DNMT1, 3a, and 3b was associated with PDAC tumorigenesis and progression. Specifically, aberrant expression of DNMT1, 3a and 3b proteins was found in PDAC tissues, and DNMT1 expression was significantly associated with alcohol consumption and poor survival of PDAC patients. Knockdown of DNMT1 and DNMT3b expression significantly inhibited the viability of PDAC cells, decreased the number of cells in the S-phase, increased the number of cells in the G0/G1-phase, induced apoptosis, upregulated the mRNA expression of the cell cycle-related CDKN1A gene and the pro-apoptotic Bax gene, and demethylated Bax promoter DNA. Although a synergistic effect of DNMT1 and DNMT3b siRNA knockdown was not observed, DNMT silencing may be a potential novel treatment strategy for PDAC.

Previous studies have demonstrated that hypermethylation of tumor suppressor gene promoters is crucial for cancer initiation and progression [21]. Many CpG islands in the gene promoters have been reported to be hypermethylated in PDAC [22], such as SPARC [23], CDKN2A (p16) [24], RASSF1A [25], WWOX [25] and CXCR4 [26]. It has been speculated that the aberrant hypermethylation of tumor suppressor genes could be caused by abnormal upregulation of DNMT expression. In previous studies, it was shown that the overexpression of DNMT1 $[16,17]$ and DNMT3a [26] in PDAC tissues was associated with poor overall survival, but the association data were inconsistent. In the current study, expression of DNMT1, 3a and 3b proteins was simultaneously analyzed in PDAC tissues and a more detailed investigation of clinicopathological characteristics was performed. A comprehensive knowledge about the pathogenic characteristics of DNMTs involved in PDAC tumorigenesis was gathered and our data indicate that overexpression of DNMT1 and DNMT3b play a key role in PDAC tumorigenesis and progression.

Hypermethylation of tumor suppressor genes is caused by aberrant up-regulation of DNMT protein expression and enzyme activity. Thus, many researchers have targeted DNTM as a novel treatment strategy for tumors In addition to cytosine analogues capable of trapping DNMTs onto DNA, inhibition of DNMT mRNA expression through siRNA [15,27], antisense [15], irradiation $[28,29]$ and mediation through the Hedgehog pathway [18] have been explored in previous studies. Some studies have also investigated the synergistic knockdown of DNMT1 and DNMT3b [27,30,31]. In fact, our data did

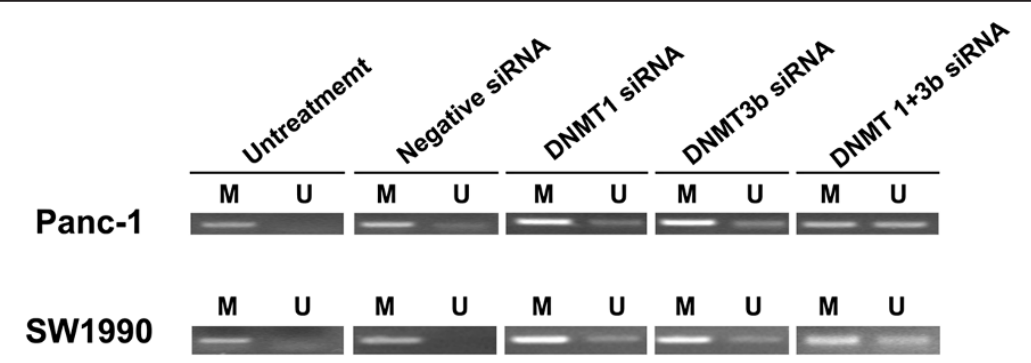

Figure 6 Demethylation of Bax gene promoter was determined by MSP method after DNMT1 siRNA, DNMT3b siRNA, or their combination was transiently transfected into PDAC cell lines. M, Methylation. U, Un-methylation. 
not show a synergistic effect after combination of DNMT1 and DNMT3b siRNA in PDAC cells. These results were in agreement with previous studies in breast [31] and PDAC cell lines [27], as well as in lung, esophageal cancer, and malignant pleural mesothelioma cells [32]. In contrast, other studies have shown a synergistic effect in an ovarian cancer CP70 cell line [33], a cholangiocarcinoma QBC-939 cell line [31] and a colorectal cancer cell line [34]. We speculated that this discrepancy might be attributed to different hypermethylation mechanisms in the different types of cancers. For example, PDAC may have its own gene methylation profile during tumorigenesis and progression [35,36]. Thus, further in vivo studies are needed to confirm whether there is a synergistic effect after combination of DNMT1 and DNMT3b siRNA in PDAC.

As stated, DNMT1 and DNMT3b siRNA transfection reduced PDAC cell viability, arrested cells at the G0/G1phases, decreased the number of cells at the S-phase of the cell cycle and induced apoptosis of PDAC cells. In order to explore the associated mechanism, we analyzed the expression of $\mathrm{Bcl}-2$ and Bax mRNA [37]. In this study, Bax mRNA was significantly upregulated, while Bcl-2 mRNA was not altered. This may have been due to demethylation of the Bax gene promoter after DNMT1 and DNMT3b siRNA transfection. This finding is in agreement with the hypothesis that Bax may be more vulnerable to environmental factors than Bcl-2 in PDAC [38]. In addition, the expression of CDKN1A mRNA was analyzed because CDKN1A mediates cell cycle arrest in response to the p53 checkpoint pathway during PDAC tumorigenesis [39-41]. CDKN1A mRNA was significantly upregulated after DNMT1 and DNMT3b siRNA transfection. The results were consistent with previous studies showing that DNMT inhibition led to a rapid upregulation of CDKN1A expression [42].

The results of the present study demonstrated that DNMT1, 3a and 3b proteins were highly expressed in PDAC tissues, suggesting that DNMTs may be targets for carcinogenic environmental factors to affect tumor suppressor gene methylation. Knockdown of DNMT expression is a potential strategy for PDAC treatment.

\section{Additional file}

Additional file 1: Table S1. Primers for Real-time RT-PCR. Table S2. Methylation-specific PCR primers for Bax gene promoter.Table $\mathbf{S 3}$. Association of DNMT1, 3a, or 3b expression with clinicopathological characteristics for PDAC patients. Table S4. Univariate survival analysis (Log Rank) of the clinicopathological characteristics of PDAC patients. Table S5. Multivariate survival analysis (Cox regression) of the clinicopathological characteristics of PDAC patients.

\section{Competing interests}

There are no competing interests to declare.

\section{Authors' contributions}

SDL, ZSL and JG designed the study. LHW and JG wrote the manuscript. JKX and HXM collected the samples. JMZ and HXM performed the immunohistochemistry and scoring. JJ and KXW performed the GRT-PCR analysis. HYW carried out cell culture. JG, LHW and JKX analyzed data. All authors read and approved the final manuscript.

\section{Acknowledgements}

The project was supported in part by grants from National Natural Science Foundation of China (No. 30910103911, No. 81272663), the National Key Technology R\&D Program (No. 2006BAI02A12), and the Key Scientific and Technological Project of Shanghai (No.11441901800). The authors also would like to thank SBC Company for their Pathologic analysis support and Oebiotech Company and Biotecan Company for gene expression detection systems.

\section{Author details}

'Department of Gastroenterology, Changhai Hospital, The Second Military Medical University, Shanghai 200433, China. ${ }^{2}$ Department of Gastroenterology, Kunshan Hospital of Traditional Chinese Medicine, Kunshan, China. ${ }^{3}$ Department of Pathology, Changhai Hospital, The Second Military Medical University, Shanghai 200433, China. ${ }^{4}$ Shanghai Biochip Co. Ltd, Shanghai 200433, China.

Received: 19 August 2013 Accepted: 31 October 2013 Published: 5 November 2013

\section{References}

1. Effenberger KE, Schroeder C, Eulenburg C, Reeh M, Tachezy M, Riethdorf S, Vashist YK, Izbicki JR, Pantel K, Bockhorn M: Disseminated tumor cells in pancreatic cancer-an independent prognosticator of disease progression and survival. Int J Cancer 2012, 131:E475-E483.

2. Van den Broeck A, Vankelecom H, Van Eijsden R, Govaere O, Topal B: Molecular markers associated with outcome and metastasis in human pancreatic cancer. J Exp Clin Cancer Res 2012, 31:68.

3. Lucenteforte E, La Vecchia C, Silverman D, Petersen GM, Bracci PM, Ji BT, Bosetti C, Li D, Gallinger S, Miller AB, Bueno-de-Mesquita HB, Talamini R, Polesel J, Ghadirian P, Baghurst PA, Zatonski W, Fontham E, Bamlet WR, Holly EA, Gao YT, Negri E, Hassan M, Cotterchio M, Su J, Maisonneuve P, Boffetta P, Duell EJ: Alcohol consumption and pancreatic cancer: a pooled analysis in the International Pancreatic Cancer Case-control Consortium (PanC4). Ann Oncol 2012, 23:374-382

4. Bidel S, Hu G, Jousilahti P, Pukkala E, Hakulinen T, Tuomilehto J: Coffee consumption and risk of gastric and pancreatic cancer-A prospective cohort study. Int J Cancer 2013, 132:1651-1659.

5. Rohrmann S, Linseisen J, Nothlings U, Overvad K, Egeberg R, Tjonneland A, Boutron-Ruault MC, Clavel-Chapelon F, Cottet V, Pala V, Tumino R, Palli D, Panico $S$, Vineis $P$, Boeing $H$, Pischon $T$, Grote $V$, Teucher B, Khaw KT, Wareham NJ, Crowe FL, Goufa I, Orfanos P, Trichopoulou A, Jeurnink SM, Siersema PD, Peeters PH, Brustad M, Engeset D, Skeie G, Duell EJ, Amiano P, Barricarte A, Molina-Montes E, Rodriguez L, Tormo MJ, Sund M, Ye W, Lindkvist B, Johansen D, Ferrari P, Jenab M, Slimani N, Ward H, Riboli E, Norat T, Bueno-de-Mesquita HB: Meat and fish consumption and risk of pancreatic cancer: Results from the European Prospective Investigation into Cancer and Nutrition. Int J Cancer 2013, 132:617-24.

6. Sharma S, Kelly TK, Jones PA: Epigenetics in cancer. Carcinogenesis 2010, 31:27-36.

7. Song J, Rechkoblit O, Bestor TH, Patel DJ: Structure of DNMT1-DNA complex reveals a role for autoinhibition in maintenance DNA methylation. Science 2011, 331:1036-40.

8. Ding $Y B$, Long $C L$, Liu $X Q$, Chen $X M$, Guo LR, Xia $Y Y$, He JL, Wang $Y X$ : 5-aza-2'-deoxycytidine leads to reduced embryo implantation and reduced expression of DNA methyltransferases and essential endometrial genes. PLoS One 2012, 7:e45364.

9. Pawlak M, Jaenisch R: De novo DNA methylation by Dnmt3a and Dnmt3b is dispensable for nuclear reprogramming of somatic cells to a pluripotent state. Genes Dev 2011, 25:1035-40.

10. Kanai $Y$ : Alterations of DNA methylation and clinicopathological diversity of human cancers. Pathol Int 2008, 58:544-58.

11. Jurkowski TP, Jeltsch A: On the evolutionary origin of eukaryotic DNA methyltransferases and Dnmt2. PLoS One 2011, 6:e28104. 
12. Yang J, Wei X, Wu Q, Xu Z, Gu D, Jin Y, Shen Y, Huang H, Fan H, Chen J: Clinical significance of the expression of DNA methyltransferase proteins in gastric cancer. Mol Med Report 2011, 4:1139-43.

13. Girault I, Tozlu S, Lidereau R, Bieche I: Expression analysis of DNA methyltransferases $1,3 \mathrm{~A}$, and $3 \mathrm{~B}$ in sporadic breast carcinomas. Clin Cancer Res 2003, 9:4415-22.

14. Krifa M, Alhosin M, Muller CD, Gies JP, Chekir-Ghedira L, Ghedira K, Mely Y, Bronner C, Mousli M: Limoniastrum guyonianum aqueous gall extract induces apoptosis in human cervical cancer cells involving p16 INK4A re-expression related to UHRF1 and DNMT1 down-regulation. J Exp Clin Cancer Res 2013, 32:30.

15. Xu M, Gao J, Du YQ, Gao DJ, Zhang YQ, Li ZS, Zhang YL, Gong YF, Xu P: Reduction of pancreatic cancer cell viability and induction of apoptosis mediated by siRNA targeting DNMT1 through suppression of total DNA methyltransferase activity. Mol Med Report 2010, 3:699-704.

16. Wang W, Gao J, Man XH, Li ZS, Gong YF: Significance of DNA methyltransferase-1 and histone deacetylase-1 in pancreatic cancer. Oncol Rep 2009, 21:1439-47.

17. Peng DF, Kanai Y, Sawada M, Ushijima S, Hiraoka N, Kosuge T, Hirohashi S: Increased DNA methyltransferase 1 (DNMT1) protein expression in precancerous conditions and ductal carcinomas of the pancreas. Cancer Sci 2005, 96:403-8.

18. He S, Wang F, Yang L, Guo C, Wan R, Ke A, Xu L, Hu G, Xu X, Shen J, Wang $X$ : Expression of DNMT1 and DNMT3a are regulated by GLI1 in human pancreatic cancer. PLoS One 2011, 6:e27684.

19. Zhang JJ, Zhu Y, Zhu Y, Wu JL, Liang WB, Zhu R, Xu ZK, Du Q, Miao Y: Association of increased DNA methyltransferase expression with carcinogenesis and poor prognosis in pancreatic ductal adenocarcinoma. Clin Transl Oncol 2012, 14:116-24.

20. Ding WJ, Fang JY, Chen XY, Peng YS: The expression and clinical significance of DNA methyltransferase proteins in human gastric cancer. Dig Dis Sci 2008, 53:2083-9.

21. Ron-Bigger S, Bar-Nur O, Isaac S, Bocker M, Lyko F, Eden A: Aberrant epigenetic silencing of tumor suppressor genes is reversed by direct reprogramming. Stem Cells 2010, 28:1349-54.

22. Vincent A, Omura N, Hong SM, Jaffe A, Eshleman J, Goggins M: Genome-wide analysis of promoter methylation associated with gene expression profile in pancreatic adenocarcinoma. Clin Cancer Res 2011 17:4341-54

23. Gao J, Song J, Huang H, Li Z, Du Y, Cao J, Li M, Lv S, Lin H, Gong Y: Methylation of the SPARC gene promoter and its clinical implication in pancreatic cancer. J Exp Clin Cancer Res 2010, 29:28.

24. Delpu Y, Hanoun N, Lulka H, Sicard F, Selves J, Buscail L, Torrisani J, Cordelier P: Genetic and epigenetic alterations in pancreatic carcinogenesis. Curr Genomics 2011, 12:15-24

25. Dammann R, Schagdarsurengin U, Liu L, Otto N, Gimm O, Dralle H, Boehm BO, Pfeifer GP, Hoang-Vu C: Frequent RASSF1A promoter hypermethylation and K-ras mutations in pancreatic carcinoma. Oncogene 2003, 22:3806-12.

26. Li A, Omura N, Hong SM, Goggins M: Pancreatic cancer DNMT1 expression and sensitivity to DNMT1 inhibitors. Cancer Biol Ther 2010, 9:321-329.

27. Przybylski M, Kozlowska A, Pietkiewicz PP, Lutkowska A, Lianeri M, Jagodzinski PP: Increased CXCR4 expression in AsPC1 pancreatic carcinoma cells with RNA interference-mediated knockdown of DNMT1 and DNMT3B. Biomed Pharmacother 2010, 64:254-8.

28. Amato RJ, Stephenson J, Hotte S, Nemunaitis J, Belanger K, Reid G, Martell RE: MG98, a second-generation DNMT1 inhibitor, in the treatment of advanced renal cell carcinoma. Cancer Invest 2012, 30:415-21.

29. Ma JX, Jin ZD, Si PR, Liu Y, Lu Z, Wu HY, Pan X, Wang LW, Gong YF, Gao J, Zhao-shen L: Continuous and low-energy 125 I seed irradiation changes DNA methyltransferases expression patterns and inhibits pancreatic cancer tumor growth. J Exp Clin Cancer Res 2011, 30:35.

30. Zhang S, Zeng F, Peng S, Zhu C, Li H, Wang L: Effects on biological behavior of bladder carcinoma T24 cells via silencing DNMT1 and/or DNMT3b with shRNA in vitro. J Huazhong Univ Sci Technolog Med Sci 2009, 29:215-9.

31. Zuo S, Luo J, Liu M, Xu L, Dong J, Guo W, Zou S: Suppressing effects of down-regulating DNMT1 and DNMT3b expression on the growth of human cholangiocarcinoma cell line. J Huazhong Univ Sci Technolog Med Sci 2008, 28:276-80
32. Kassis ES, Zhao M, Hong JA, Chen GA, Nguyen DM, Schrump DS: Depletion of DNA methyltransferase 1 and/or DNA methyltransferase $3 \mathrm{~b}$ mediates growth arrest and apoptosis in lung and esophageal cancer and malignant pleural mesothelioma cells. J Thorac Cardiovasc Surg 2006, 131:298-306.

33. Leu YW, Rahmatpanah F, Shi H, Wei SH, Liu JC, Yan PS, Huang TH: Double RNA interference of DNMT3b and DNMT1 enhances DNA demethylation and gene reactivation. Cancer Res 2003, 63:6110-5.

34. Rhee I, Bachman KE, Park BH, Jair KW, Yen RW, Schuebel KE, Cui H, Feinberg AP, Lengauer C, Kinzler KW, Baylin SB, Vogelstein B: DNMT1 and DNMT3b cooperate to silence genes in human cancer cells. Nature 2002, 416:552-6.

35. Kang S, Kim JW, Kang GH, Lee S, Park NH, Song YS, Park SY, Kang SB, Lee HP: Comparison of DNA hypermethylation patterns in different types of uterine cancer: cervical squamous cell carcinoma, cervical adenocarcinoma and endometrial adenocarcinoma. Int J Cancer 2006 118:2168-71.

36. Xu Y, Hu B, Choi AJ, Gopalan B, Lee BH, Kalady MF, Church JM, Ting AH: Unique DNA methylome profiles in CpG island methylator phenotype colon cancers. Genome Res 2012, 22:283-291.

37. Ling $Q$, Xu X, Wei X, Wang W, Zhou B, Wang B, Zheng S: Oxymatrine induces human pancreatic cancer PANC-1 cells apoptosis via regulating expression of $\mathrm{Bcl}-2$ and IAP families, and releasing of cytochrome $\mathrm{C}$. J Exp Clin Cancer Res 2011, 30:66.

38. Friess H, Lu Z, Graber HU, Zimmermann A, Adler G, Korc M, Schmid RM, Buchler MW: bax, but not bcl-2, influences the prognosis of human pancreatic cancer. Gut 1998, 43:414-21.

39. Li G, Zhang Z, Wang R, Ma W, Yang Y, Wei J, Wei Y: Suppression of STIM1 inhibits human glioblastoma cell proliferation and induces $\mathrm{G0} / \mathrm{G} 1$ phase arrest. J Exp Clin Cancer Res 2013, 32:20.

40. Zhang Z, Wang Z, Liu X, Wang J, Li F, Li C, Shan B: Up-regulation of p21WAF1/CIP1 by small activating RNA inhibits the in vitro and in vivo growth of pancreatic cancer cells. Tumori 2012, 98:804-11.

41. Bendjennat M, Boulaire J, Jascur T, Brickner H, Barbier V, Sarasin A, Fotedar A, Fotedar R: UV irradiation triggers ubiquitin-dependent degradation of p21 (WAF1) to promote DNA repair. Cell 2003, 114:599-610.

42. Milutinovic S, Zhuang Q, Niveleau A, Szyf M: Epigenomic stress response. Knockdown of DNA methyltransferase 1 triggers an intra-S-phase arrest of DNA replication and induction of stress response genes. J Biol Chem 2003, 278:14985-95.

doi:10.1186/1756-9966-32-86

Cite this article as: Gao et al.: Aberrant DNA methyltransferase expression in pancreatic ductal adenocarcinoma development and progression. Journal of Experimental \& Clinical Cancer Research 2013 32:86.

\section{Submit your next manuscript to BioMed Central and take full advantage of:}

- Convenient online submission

- Thorough peer review

- No space constraints or color figure charges

- Immediate publication on acceptance

- Inclusion in PubMed, CAS, Scopus and Google Scholar

- Research which is freely available for redistribution 